OPEN ACCESS

Edited by: Xin $X u$,

Sichuan University, China

Reviewed by: Jessica Kajfasz, University of Florida, United States Sang-Joon Ahn, University of Florida, United States

*Correspondence: Yaping Gou gouyp@lzu.edu.cn Bin Liu

liubkq@lzu.edu.cn

Specialty section:

This article was submitted to Microbiome in Health and Disease, a section of the journal

Frontiers in Cellular and Infection Microbiology

Received: 27 September 2021 Accepted: 28 October 2021 Published: 19 November 2021

Citation:

Gou Y, Jin W, He Y, Luo Y, Si R, He Y, Wang Z, Li J and Liu B (2021) Effect of Cavity Cleanser With Long-Term Antibacterial and Anti-Proteolytic Activities on Resin-Dentin Bond Stability. Front. Cell. Infect. Microbiol. 11:784153. doi: $10.3389 /$ fcimb.2021.784153

\section{Effect of Cavity Cleanser With Long-Term Antibacterial and Anti-Proteolytic Activities on Resin-Dentin Bond Stability}

\author{
Yaping Gou*, Wei Jin, Yanning He, Yu Luo, Ruirui Si, Yuan He, Zhongchi Wang, \\ Jing Li and Bin Liu*
}

Key Laboratory of Dental Maxillofacial Reconstruction and Biological Intelligence Manufacturing, Gansu Province, School of Stomatology, Lanzhou University, Lanzhou, China

Objective: Secondary caries caused by oral microbiome dysbiosis and hybrid layer degradation are two important contributors to the poor resin-dentin bond durability. Cavity cleansers with long-term antimicrobial and anti-proteolytic activities are in demand for eliminating bacteria-induced secondary caries and preventing hybrid layers from degradation. The objectives of the present study were to examine the long-term antimicrobial effect and anti-proteolytic potential of poly(amidoamine) dendrimers with amino terminal groups (PAMAM- $\mathrm{NH}_{2}$ ) cavity cleanser.

Methods: Adsorption tests by attenuated total reflectance-infrared (ATR-IR) spectroscopy and confocal laser scanning microscopy (CLSM) were first performed to evaluate whether the PAMAM- $\mathrm{NH}_{2}$ cavity cleanser had binding capacity to dentin surface to fulfill its relatively long-term antimicrobial and anti-proteolytic effects. For antibacterial testing, Streptococcus mutans, Actinomyces naes/undii, and Enterococcus faecalis were grown on dentin surfaces, prior to the application of cavity cleanser. Colony-forming unit (CFU) counts and live/dead bacterial staining were performed to assess antibacterial effects. Gelatinolytic activity within the hybrid layers was directly detected by in situ zymography. Adhesive permeability of bonded interface and microtensile bond strength were employed to assess whether the PAMAM- $\mathrm{NH}_{2}$ cavity cleanser adversely affected resin-dentin bonding. Finally, the cytotoxicity of PAMAM- $\mathrm{NH}_{2}$ was evaluated by the Cell Counting Kit-8 (CCK-8) assay.

Results: Adsorption tests demonstrated that the binding capacity of PAMAM- $\mathrm{NH}_{2}$ on dentin surface was much stronger than that of $2 \%$ chlorhexidine $(\mathrm{CHX})$ because its binding was strong enough to resist phosphate-buffered saline (PBS) washing. Antibacterial testing indicated that PAMAM- $\mathrm{NH}_{2}$ significantly inhibited bacteria grown on the dentin discs as compared with the control group ( $p<0.05)$, which was comparable with the antibacterial activity of $2 \% \mathrm{CHX}(\mathrm{p}>0.05)$. Hybrid layers conditioned with PAMAM- $\mathrm{NH}_{2}$ showed significant decrease in gelatin activity as compared with the control group. Furthermore, PAMAM- $\mathrm{NH}_{2}$ pretreatment did not adversely affect resin-dentin 
bonding because it did not decrease adhesive permeability and microtensile strength. CCK-8 assay showed that PAMAM- $\mathrm{NH}_{2}$ had low cytotoxicity on human dental pulp cells (HDPCs) and L929.

Conclusions: PAMAM- $\mathrm{NH}_{2}$ cavity cleanser developed in this study could provide simultaneous long-term antimicrobial and anti-proteolytic activities for eliminating secondary caries that result from a dysbiosis in the oral microbiome and for preventing hybrid layers from degradation due to its good binding capacity to dentin collagen matrix, which are crucial for the maintenance of resin-dentin bond durability.

Keywords: antibacterial, endogenous dentin proteases, cavity cleanser, resin-dentin bonds, poly (amidoamine) dendrimers

\section{INTRODUCTION}

Secondary caries caused by oral microbiome dysbiosis and degradation of hybrid layer via endogenous dentin proteases are two major challenges encountered in durable resin-dentin bond stability (Gou et al., 2018a). In contemporary minimally invasive dentistry, partial retention of caries-infected dentin is currently recommended to preserve tooth structure and avoid damage to the dental pulp complex (Thompson et al., 2008; Walsh and Brostek, 2013). Nevertheless, entrapped bacteria and their by-products through interfacial gaps between the tooth and the restoration leads to secondary caries that is described as a microbial disease that results from "a dysbiosis in the oral microbiome" (Tanner et al., 2016) and to restoration failure over time (Nyvad and Kilian, 1987; Türkün et al., 2006).

Hybrid layer degradation, caused by hydrolysis of adhesive resin (Breschi et al., 2008; Tjäderhane et al., 2013) and degradation of demineralized collagen matrices in aqueous environments (Mazzoni et al., 2015), is the other challenge in achieving durability of bonds made by resins in dentin. During the acidetching phase of dentin bonding, endogenous dentin protease such as matrix metalloproteinases (MMPs) and cysteine cathepsins that are normally embedded within the collagen matrix by apatite crystallites become exposed and activated by acid etchants. Subsequent application of acidic resin monomers present in dentin adhesives further promotes activities of these proteases (Tay et al., 2006; Osorio et al., 2011; Frassetto et al., 2016). The activated, matrix-bound protease can progressively degrade denuded collagen fibrils within the hybrid layers, leading to deterioration of resin-dentin bonds over time (Frassetto et al., 2016).

To prolong the durability of resin-dentin interfacial bonds, the aforementioned two challenges should be concomitantly addressed. The use of cavity cleanser with antibacterial and anti-proteolytic properties is in demand. Chlorhexidine (CHX) possesses broad spectrum antibacterial (Twetman, 2004) and anti-proteolytic activities (Scaffa et al., 2012) and has been commonly used as an effective agent to disinfect dentin cavity (Ersin et al., 2008). Nevertheless, CHX is water-soluble and has weak binding affinity for the demineralized dentin collagen matrix (Slee and Tanzer, 1979; Blackburn et al., 2007). It eventually desorbs from the exposed collagen fibrils and slowly leaches out from the hybrid layers over time, thus compromising its long-term antimicrobial and anti-proteolytic effects (Tezvergil-Mutluay et al., 2011).

Recently, poly(amidoamine) dendrimers with amino terminal groups (PAMAM- $\mathrm{NH}_{2}$ ) have been extensively investigated as promising antimicrobial agents due to a great number of positive charges on the protonated amino groups on their exterior (Castonguay et al., 2012; Gou et al., 2017). With numerous positively charged amino groups, $\mathrm{PAMAM}-\mathrm{NH}_{2}$ is capable of attaching to and puncturing bacteria (Mintzer et al., 2012) cell walls as well as possessing a strong affinity for the denuded dentin collagen (Liang et al., 2015). Hence, it is speculated that when PAMAM- $\mathrm{NH}_{2}$ is applied to acid-etched dentin, it would strongly absorb on exposed collagen fibrils to provide relatively long-lasting antimicrobial effectiveness. However, there has been no report whether PAMAM- $\mathrm{NH}_{2}$ has inhibitory effects on endogenous dentin proteases.

Accordingly, the objectives of this study were to develop a new dentin cavity cleanser containing PAMAM- $\mathrm{NH}_{2}$, to explore its effect of against bacteria grown on dentin surfaces, and to assess the enzyme activity of the resin-dentin interface using in situ zymography and functional enzyme activity assays. It was hypothesized that 1) the PAMAM- $\mathrm{NH}_{2}$ cavity cleanser has longterm inhibitory effects on bacteria grown on dentin blocks; 2 ) the PAMAM- $\mathrm{NH}_{2}$ cavity cleanser has inhibitory effects on soluble MMP-9 activities; 3 ) the PAMAM- $\mathrm{NH}_{2}$ cavity cleanser has longterm inhibitory effects on endogenous dentin proteases; and 4) treatment of dentin surface with PAMAM- $\mathrm{NH}_{2}$ cavity cleanser does not adversely affect dentin bond strength.

\section{MATERIALS AND METHODS}

PAMAM- $\mathrm{NH}_{2}$ utilized in the present work was purchased from ChenYuan Dendrimer Technology Co., Ltd (Weihai, Shandong, China).

\subsection{Binding Capacity of PAMAM- $\mathrm{NH}_{2}$ to Demineralized Dentin}

PAMAM- $\mathrm{NH}_{2}$ measuring $4 \mathrm{mg} / \mathrm{ml}$ and $2 \% \mathrm{CHX}$ were separately dropped and spread on etched dentin surface using a disposable micro brush. After $60 \mathrm{~s}$ of being gently air-dried at room temperature, each dentin surface was subsequently washed with 
phosphate-buffered saline (PBS) three times and dried again. Attenuated total reflectance-infrared (ATR-IR) spectroscopy (Nicolet iS10, Thermo Scientific, USA) was performed and recorded before and after conditioning with PAMAM- $\mathrm{NH}_{2}$ and $2 \% \mathrm{CHX}$, and also after washing with PBS. Each group was performed in sextuplicate. Three independent batches were conducted for the experiment.

Fluorescein isothiocyanate (FITC)-labeled PAMAM-NH $\mathrm{N}_{2}$ was prepared by mixing equimolar amounts of an FITC solution (in acetone) with an aqueous PAMAM- $\mathrm{NH}_{2}$ solution overnight in the dark under stirring (Gou et al., 2017). FITC-labeled PAMAM$\mathrm{NH}_{2}(4 \mathrm{mg} / \mathrm{ml}, 50 \mu \mathrm{l})$ or FITC was respectively dropped and spread on etched dentin surface using a disposable micro brush. After $60 \mathrm{~s}$, the dentin surface was washed with PBS three times, and the specimens were dried and observed by confocal laser scanning microscopy (CLSM) (Zeiss LSM700, Germany). Quantification of the green fluorescence intensity was calculated with Image-Pro Plus 6.0 (Media Cybernetics, Inc., Silver Spring, MD, USA) to represent the relative binding capacity of PAMAM- $\mathrm{NH}_{2}$ to demineralized dentin. Each group was performed in sextuplicate. Three independent batches were conducted for the experiment.

\subsection{Antibacterial Activity Testing}

\subsubsection{Bacterial Culture}

Streptococcus mutans (ATCC 700610), Actinomyces naeslundii (ATCC 12104), and Enterococcus faecalis (ATCC 29212) were used to examine the antibacterial activities of experimental cavity cleansers. E. faecalis was grown aerobically in Brain Heart Infusion (BHI) broth at $37^{\circ} \mathrm{C}$. S. mutans and A. naeslundii were cultured in an anaerobic atmosphere of $5 \% \mathrm{CO}_{2}, 90 \% \mathrm{~N}_{2}$, and $5 \% \mathrm{H}_{2}$ at $37^{\circ} \mathrm{C}$ in $\mathrm{BHI}$ broth. For biofilm formation, the bacteria were cultured in BHI supplemented with $1 \%$ sucrose. The bacteria were incubated for $24 \mathrm{~h}$, collected by centrifugation, and rinsed three times with PBS. The bacteria were re-suspended and further diluted in $\mathrm{BHI}$ to a final density of $1.0 \times 10^{7}$ colonyforming unit $(\mathrm{CFU}) / \mathrm{ml}$. Bacteria density was measured by a microplate reader (Beckman Coulter, Inc., Indianapolis, IN, USA) at the absorbance of $600 \mathrm{~nm}$.

\subsubsection{Minimum Inhibitory Concentration}

In order to evaluate the effect of PAMAM- $\mathrm{NH}_{2}$ on planktonic bacteria, the minimum inhibitory concentration (MIC) was examined by the broth microdilution method. The PAMAM$\mathrm{NH}_{2}$ solution was added in a twofold dilution series in BHI broth in 96-well microtiter plates $\left(1.0 \times 10^{7} \mathrm{CFU} / \mathrm{ml}\right)$. After incubation overnight, bacterial growth was measured by a microplate reader at the absorbance of $600 \mathrm{~nm}$. MIC value was determined as the lowest PAMAM- $\mathrm{NH}_{2}$ concentration that inhibited at least $90 \%$ of bacterial growth compared with the PAMAM- $\mathrm{NH}_{2}$-free control. Each group was performed in sextuplicate. Three independent batches were performed for the experiment.

\subsubsection{Minimum Biofilm Eradication Concentration}

In a physiological state, bacteria tend to exist in biofilms. Bacteria in biofilms are less susceptible to stressful environmental conditions than in their planktonic state. Therefore, minimum biofilm eradication concentration (MBEC) was assessed to evaluate whether PAMAM- $\mathrm{NH}_{2}$ has inhibitory effects on biofilms. MBEC was assessed by microtiter plate assay. The testing was started by growing the biofilm first by incubating the suspension of $S$. mutans and A. naeslundii for $24 \mathrm{~h}$ and $E$. faecalis for 7 days at $37^{\circ} \mathrm{C}$. Then, each microplate well was gently washed three times with PBS to remove unattached bacteria, and PAMAM- $\mathrm{NH}_{2}$ with different concentrations was added. After that, the microplates were incubated for $24 \mathrm{~h}$ (S. mutans and A. naeslundii) or 7 days (E. faecalis) at $37^{\circ} \mathrm{C}$ and were rinsed with PBS. The biofilm was added with $1 \%$ of crystal violet solution and cultured at room temperature. The well was gently washed with PBS for three times to remove excess crystal violet and incubated with $95 \%$ ethanol by shaking for $15 \mathrm{~min}$. The optical density at $595 \mathrm{~nm}$ was measured with a microplate reader (Model 3550, Bio-Rad). Each group was performed in sextuplicate. Three independent batches were conducted for the experiment.

\subsubsection{Cell Counting Kit-8 Counts}

$S$. mutans, A. naeslundii, or E. faecalis biofilm was grown on the surface of dentin discs. Each biofilm-containing dentin disc was conditioned with PAMAM- $\mathrm{NH}_{2}$ and $2 \% \mathrm{CHX}$ and kept for $60 \mathrm{~s}$. The dentin blocks were gently rinsed and transferred into Petri dishes with $1 \mathrm{ml}$ of PBS. The dishes were ultrasonicated to collect biofilms. The collected biofilms were cultured on BHI agar plates, and their viability was assessed by CFU counting after a serial dilution in PBS. Each group was performed in sextuplicate. Three independent batches were conducted for the experiment.

\subsubsection{Live/Dead Bacterial Staining}

$S$. mutans, A. naeslundii, or E. faecalis biofilm grown on the surface of dentin discs was treated with a LIVE/DEAD BacLight Bacterial Viability Kit (Molecular Probes, Invitrogen Corp., Carlsbad, CA, USA). Sterilized dentin blocks were incubated with each bacterium at $37^{\circ} \mathrm{C}$ for $24 \mathrm{~h}$ (S. mutans and A. naeslundii) or 7 days (E. faecalis) and were gently washed three times with PBS to remove unattached bacteria. Each biofilm-containing dentin disc was conditioned with PAMAM- $\mathrm{NH}_{2}$ and $2 \% \mathrm{CHX}$ by adding $100 \mu \mathrm{l}$ of each cavity cleanser onto the dentin surface and kept for $60 \mathrm{~s}$. Then the dentin blocks were treated with $2.5 \mu \mathrm{M}$ of SYTO 9 and propidium iodide in the dark according to the instructions. Stained dentin blocks were visualized with a CLSM (LSM 780, Carl Zeiss, Oberkochen, Germany) equipped with a $20 \times$ objective lens by the channel set at excitation/emission wavelengths $480 / 500 \mathrm{~nm}$ for SYTO 9, and 590/635 $\mathrm{nm}$ for propidium iodide. Live bacteria are dyed green, dead bacteria are dyed red, and adjacent live and dead bacteria are shown as yellow when they are merged. Quantification of dead and live bacteria was calculated based on the value of relative green and red fluorescence by Image-Pro Plus 6.0 software. Each group was performed in sextuplicate. Three independent batches were conducted for the experiment.

\subsection{Analysis of the Effect of PAMAM-NH on Matrix Metalloproteinases}

\subsubsection{Inhibition of Soluble rhMMP-9}

The inhibitory effects of PAMAM- $\mathrm{NH}_{2}$ and $2 \% \mathrm{CHX}$ on soluble purified recombinant human (rh) MMP-9 were assessed using purified rhMMP-9 (AS-55576) and the Sensolyte Generic MMP 
assay kit (AS-72095) (all from AnaSpec Inc., CA, USA). The MMP assay kit contains an intact substrate (thiopeptolide) that is disintegrated by MMPs to release a colored product, 2-nitro-5thiobenzoic acid.

A series of PAMAM- $\mathrm{NH}_{2}$ solutions $(0.5,1,2,4,8$, and $16 \mathrm{mg} /$ $\mathrm{ml}$ ) were prepared as test agents. The substrate solution provided by the assay kit was prepared at $0.2 \mathrm{mM}$. In the experimental groups, the well contained $2 \mu \mathrm{l}$ of rhMMP-9, $50 \mu$ l of substrate solution, and $10 \mu \mathrm{l}$ of potential MMP inhibitor.

The control groups included 1) the positive control group: rhMMP-9 enzyme only without the anti-MMP agent; 2) the inhibitor control group: rhMMP-9 enzyme and MMP inhibitor (GM6001); 3) the test compound control group: assay buffer and various concentrations of PAMAM- $\mathrm{NH}_{2}$ solutions; and 4) the substrate control group: assay buffer only. The reagents on the plate were shaken for $30 \mathrm{~s}$ to mix completely. Readings were measured every $10 \mathrm{~min}$ for $60 \mathrm{~min}$. The intensity of color was detected using a microplate reader at $412 \mathrm{~nm}$. The potency of MMP-9 inhibition by GM6001 (known MMP inhibitor) and the six concentrations of PAMAM- $\mathrm{NH}_{2}$ were exhibited as percentages of the adjusted absorbance of the "positive control." Percent inhibition of the MMP (\%) was calculated as $1-\left([\mathrm{A}]_{\text {test }}\right.$ compound group $-[\mathrm{A}]_{\text {test }}$ compound control $) /$ $\left([\mathrm{A}]_{\text {positive control }}-[\mathrm{A}]_{\text {substrate control }}\right)$, where $[\mathrm{A}]$ represents the absorbance values of the wells. Each specimen was performed in sextuplicate $(\mathrm{N}=6)$. Three independent batches were conducted for the experiment.

\subsubsection{In Situ Zymography}

Ten teeth from two cavity cleanser group were used for in situ zymography of the bonded interface. After being treated with $37 \%$ phosphoric acid, the dentin blocks were conditioned with each cavity cleanser for $60 \mathrm{~s}$ and gently air-dried. After being bonded with adhesive, a 2-mm-thick layer of flowable resin composite was placed and light-cured. After $24 \mathrm{~h}$ of storage in deionized water, the bonded samples were cut vertically into 1mm-thick slabs to expose the resin-dentin interface.

The bonded slab was fixed to a glass slide and polished to approximately $50-\mu \mathrm{m}$ thickness. The EnzChek ${ }^{\mathrm{TM}}$ Gelatinase/ Collagenase Assay Kit (E-12055, Molecular Probes, Eugene, OR, USA) was employed for in situ zymography to identify sites of MMP activity within the hybrid layers. Briefly, the 1.0 $\mathrm{mg} / \mathrm{ml}$ stock solution of self-quenched fluorescein-conjugated gelatin was diluted by adding deionized water and mixing with anti-fading agent. Then, $50 \mu \mathrm{l}$ of the self-quenched fluorescent gelatin mixture was dropped on top of each bonded slab and covered with a coverslip. The slides were kept away from light and incubated in a humidity chamber at $37^{\circ} \mathrm{C}$ for $48 \mathrm{~h}$.

A two-photon CLSM (LSM 780, Carl Zeiss, Thornwood, NY, USA) was used to acquire images using a $40 \times$ oil immersion objective lens, with the channels set at $488 / 530 \mathrm{~nm}$ (excitation/ emission wavelengths). Green fluorescence derived from dequenched fluorescein released from disintegrated gelatin was imaged. Sections that were $85 \mu \mathrm{m}$ thick were acquired from different focal planes of each bonded specimen. The images were stacked and processed with ZEN 2010 software (Carl Zeiss). The image-Pro Plus 6.0 software was employed to quantify the green fluorescence intensity. Each group was performed in sextuplicate. Three independent batches were conducted for the experiment.

\subsection{Assessment of the Impact of PAMAM- $\mathrm{NH}_{2}$ on Resin-Dentin Bonding}

\subsubsection{Adhesive Permeation of Bonded Interface}

Twenty freshly extracted and intact human third molars were collected for permeability evaluation of adhesive. The dentin was sectioned at a distance of $2.5 \mathrm{~mm}$ away from the deepest pulpal horn using a slow-speed saw under water cooling. One drop of fluorescein sodium (Sigma-Aldrich, St Louis, MO, USA) was mixed with three drops of adhesive (Prime \& Bond ${ }^{\circledR}$ NTTM) to produce a fluorescent adhesive. The bonded dentin was glued to fenestrated Perspex discs with cyanocrylate glue. The assembly was connected via an 18-gauge stainless steel tube to fenestrated Perspex discs. The latter was placed to a column of $0.1 \%$ green fluorescent dye solution (Alexa Fluor ${ }^{\mathrm{TM}} 405$, excitation/emission: $401 / 421 \mathrm{~nm}$; Thermo Fisher Scientific) oriented $20 \mathrm{~cm}$ above the Plexiglass block to simulate pulpal pressure. This generated water pressure through the dentinal tubules during the acid-etching process, treatment with each cavity cleanser, bonding, and resin composite buildup. The setup was kept away from light and incubated for $4 \mathrm{~h}$ to enable water to continue permeating the bonded interface.

After pressure perfusion, the bonded specimen was removed from the fenestrated Perspex discs and cut vertically to get a 1 $\mathrm{mm}$ slab containing the water perfused bonded interface. Each bonded specimen was fixed to a glass slide and polished to approximately $50-\mu \mathrm{m}$ thickness. A two-photon CLSM was used to acquire images using a $40 \times$ oil immersion objective lens. Green fluorescence was imaged together with the red fluorescence derived from dyed adhesive. Sections that were 85 $\mu \mathrm{m}$ thick were acquired from different focal planes of each bonded specimen. The images were stacked and processed with ZEN 2010 software (Carl Zeiss). The image-Pro Plus 6.0 software was employed to quantify the dyed adhesive permeation. Each group was performed in sextuplicate. Three independent batches were conducted for the experiment.

\subsubsection{Bond Strengths to Dentin}

Thirty human third molars were collected for bond strength test. The teeth were cut $2-3 \mathrm{~mm}$ below the cementoenamel junction to remove roots using water-cooled low-speed cutting saw (Isomet, Buehler Ltd., Lake Bluff, IL, USA). The occlusal enamel was removed perpendicular to the longitudinal axis of each tooth to expose flat midcoronal dentin surface. The exposed midcoronal dentin surface was polished with 600-grit silicon carbide paper under water for $60 \mathrm{~s}$ to produce a standardized smear layer.

Exposed dentin surfaces were randomly allocated to two groups according to the adhesives used: Prime \& Bond ${ }^{\circledR} \mathrm{NT}^{\mathrm{TM}}$ (PB, Dentsply DeTrey, Konstanz, Germany) and Adper ${ }^{\mathrm{TM}}$ Single Bond Plus (SBP, 3M ESPE, St. Paul, MN, USA). Each specimen was treated with $37 \%$ phosphoric acid (Uni-Etch, Bisco Inc., Schaumburg, IL, USA) for $15 \mathrm{~s}$, washed with deionized water for $15 \mathrm{~s}$, and air-dried for $5 \mathrm{~s}$. Dentin surface from each adhesive 
group was further randomly assigned to one of the following three subgroups for dentin pretreatment with PAMAM- $\mathrm{NH}_{2}, 2 \%$ $\mathrm{CHX}$, and deionized water (control) $(\mathrm{N}=6)$. The etched dentin surface was pretreated with respective cavity cleanser or deionized water for $60 \mathrm{~s}$ and air-dried for $5 \mathrm{~s}$. The adhesives were placed to the etched dentin and light-cured for $15 \mathrm{~s}$ with a light-curing unit. Resin composite buildups (Z250, 3 M ESPE, St. Paul, MN, USA) were constructed.

After storage in deionized water for $24 \mathrm{~h}$, the bonded teeth were subsequently sectioned vertically to 0.9 -mm-thick slabs using a low-speed saw under water cooling. The slabs were further cut into $0.9 \mathrm{~mm} \times 0.9 \mathrm{~mm} \times 8 \mathrm{~mm}$ long beams. Each beam was attached and stressed to failure under tension using a universal tensile testing machine (HD-B609B-S, Haida International, China). Each specimen was performed in sextuplicate. Three independent batches were conducted for the experiment.

After tensile bond strength test, the dentin side of the fractured beams was detected using a stereoscopical microscope at $\times 40$ magnification to determine the failure mode. Failure modes were classified as adhesive failure (A), mixed failure $(\mathrm{M}$, failure extending into dentin or resin composite), cohesive failure in resin composite (CC), and cohesive failure in dentin (CD).

\subsection{Cytotoxicity Assay}

Human dental pulp cells (HDPCs) and mouse fibroblast cells L929 were chosen to test the cytotoxicity of PAMAM-NH $\mathrm{H}_{2}$. Freshly extracted and intact human third molars were collected, cleaned, and cut perpendicular to the longitudinal axis of each tooth to expose the pulp chamber, with the donors' written informed consent. Dental pulp tissues were gently removed by blunt non-cutting forceps and dispersed in $2 \mathrm{mg} / \mathrm{ml}$ of collagenase/dispase for $1.5 \mathrm{~h}$ to retrieve HDPCs at $37^{\circ} \mathrm{C}$. The HDPCs and L929 were cultured in Dulbecco's Modified Eagle's Medium plus 10\% heat-inactivated fetal bovine serum and $1 \%$ penicillin/streptomycin at $37^{\circ} \mathrm{C}$ in a humidified incubator supplemented with $5 \% \mathrm{CO}_{2}$. The seeded cells were subsequently cultured until $80 \%$ confluency was achieved. Four passage cells were used for the experiment.

The cytotoxicity of PAMAM- $\mathrm{NH}_{2}$ was determined by the Cell Counting Kit-8 (CCK-8) assay. Cells were seeded in a 96-well microtiter plate at a density of $1.0 \times 10^{4}$ cells/well and incubated overnight. The culture medium was replaced with $100 \mu \mathrm{l}$ of fresh culture medium containing different concentrations of PAMAM-NH $\mathrm{N}_{2}$. After incubation overnight, $10 \mu \mathrm{l}$ of CCK-8 solution was added to each well, and the microtiter plate was incubated at $37^{\circ} \mathrm{C}$ for $4 \mathrm{~h}$, after which the absorbance at $570 \mathrm{~nm}$ was determined with a microplate reader (Spectra Plus, Tecan, Zurich, Switzerland $)$. The cell viability $(\%)=\left([\mathrm{A}]_{\text {test }}-[\mathrm{A}]_{\text {blank }}\right) /$ $\left([\mathrm{A}]_{\text {control }}-[\mathrm{A}]_{\text {blank }}\right) \times 100 \%$, where $[\mathrm{A}]_{\text {test }},[\mathrm{A}]_{\text {control }}$, and $[\mathrm{A}]$ blank represent the absorbance values of the wells with cells and PAMAM-NH$H_{2}$, those with cells and without PAMAM-NH , and those without cells or PAMAM-NH$H_{2}$, respectively. For each sample, the average absorbance from six wells that run in parallel was calculated. Three independent batches were conducted for the experiment.

\subsection{Statistical Analyses}

Data were expressed as means and SDs. For each parameter to be analyzed, the data sets were evaluated for their normality (Shapiro-Wilk test) and equal variance assumptions (modified Levene's test) before use of parametric statistical methods. If those assumptions were not violated, the data sets were analyzed with one-factor ANOVA or one-factor repeated-measures ANOVA, depending on the parameter tested. Post-hoc comparisons were conducted using the Holm-Sidak procedures to identify statistical significance among groups. If the assumptions were violated, the data sets were non-linearly transformed to satisfy those assumptions before performing the aforementioned statistical procedures. For all tests, statistical significance was set at $\alpha=0.05$.

\section{RESULTS}

\subsection{Binding Capacity of PAMAM- $\mathrm{NH}_{2}$ to Demineralized Dentin}

The ATR-Fourier-transform IR (ATR-FTIR) spectra of the demineralized dentin after being conditioned with $4 \mathrm{mg} / \mathrm{ml}$ of PAMAM-NH $\mathrm{N}_{2}$ or $2 \% \mathrm{CHX}$ and after being washed with PBS are shown in Figure 1A. The peak at $1,000.1 \mathrm{~cm}^{-1}$ was due to phosphate v1, v3 functional groups, which is a characteristic peak of dentin. After being conditioned with PAMAM-NH characteristic peaks of PAMAM- $\mathrm{NH}_{2}$ were clearly detected at $3,088.52$ to $3,500 \mathrm{~cm}^{-1}$ corresponding to amide vibration and at $1,634.9 \mathrm{~cm}^{-1}$ corresponding to amide carbonyl groups, and they are related to the number of amide groups in the branches of PAMAM- $\mathrm{NH}_{2}$. The results confirmed that PAMAM-NH bound to the demineralized dentin. After thorough washing with PBS, these characteristic peaks of PAMAM- $\mathrm{NH}_{2}$ were still apparent, which indicated that PAMAM- $\mathrm{NH}_{2}$ can resist PBS washing. After being conditioned with $\mathrm{CHX}$, the presence of characteristic peaks of $\mathrm{CHX}$ was detected, as well as $\mathrm{C}-\mathrm{H}_{2}$ stretches at 2,948.5 and 2,855.0 $\mathrm{cm}^{-1}, \mathrm{C}=\mathrm{N}$ vibration at $3,319.1$ $\mathrm{cm}^{-1}$, and para-substitution of benzene rings at 1,631.5 and $1,557.0 \mathrm{~cm}^{-1}$. Following PBS washing, these characteristic peaks disappeared in CHX conditioning dentin surface, indicating that CHX was washed off by PBS.

FITC-labeled PAMAM- $\mathrm{NH}_{2}$ and free FITC were dropped onto demineralized dentin surface. After being air-dried at room temperature, the dentin surfaces were rinsed with PBS and observed by CLSM. Figure 1B shows yellow-green fluorescence, which could be clearly observed for both two groups, with an intensity value of $98.2 \% \pm 4.9 \%$ for the FITCPAMAM-NH $\mathrm{NH}_{2}$ group and $90.5 \% \pm 7.1 \%$ for the FITC group (Figure 1C). However, little fluorescence could be detected on free FITC-coated dentin surface after PBS washing (Figure 1B) reaching $26.8 \% \pm 5.7 \%$ fluorescence intensity, which was significantly lower than that of the FITC group before PBS washing (Figure 1C, $\mathrm{p}<0.05$ ). In contrast, FITC-PAMAM$\mathrm{NH}_{2}$-coated dentin retained most of the fluorescence with an intensity value of $89.6 \% \pm 3.5 \%$ (Figures $\mathbf{1 B}, \mathbf{C}$ ). There was no significant difference in the fluorescence intensity in the FITC- 
A

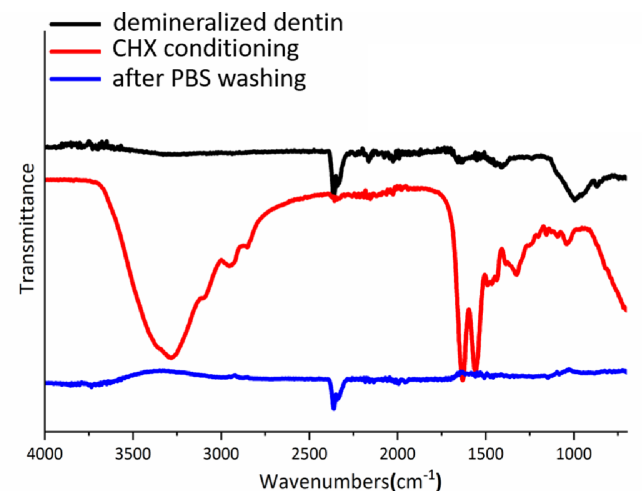

B

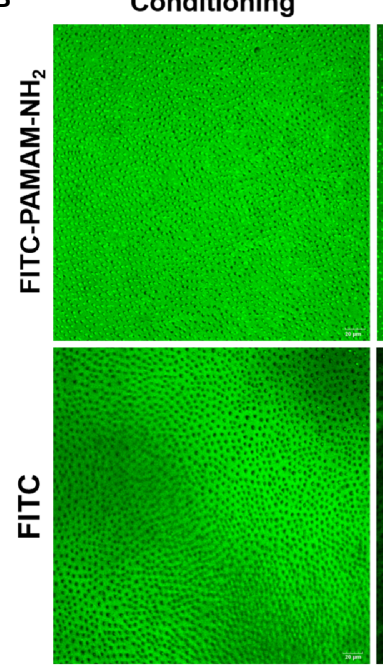

After PBS washing

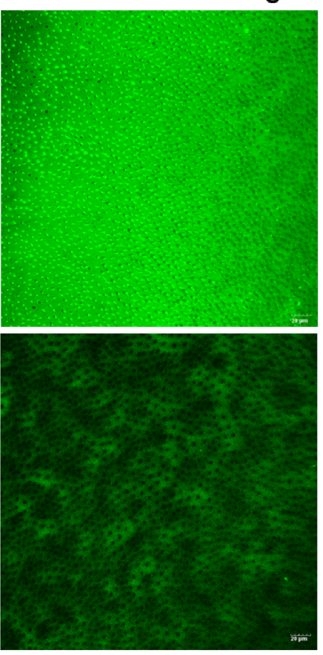

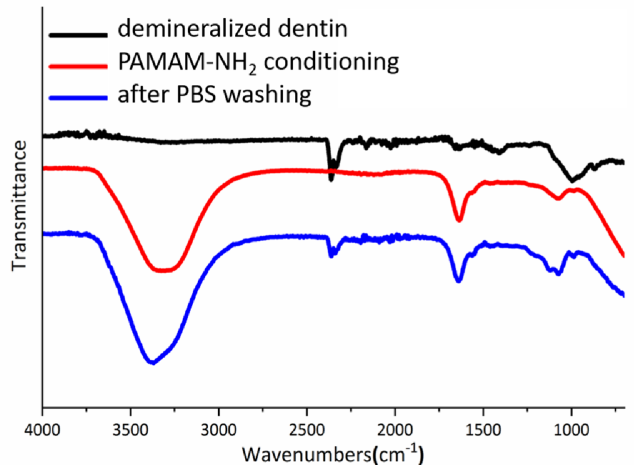

C

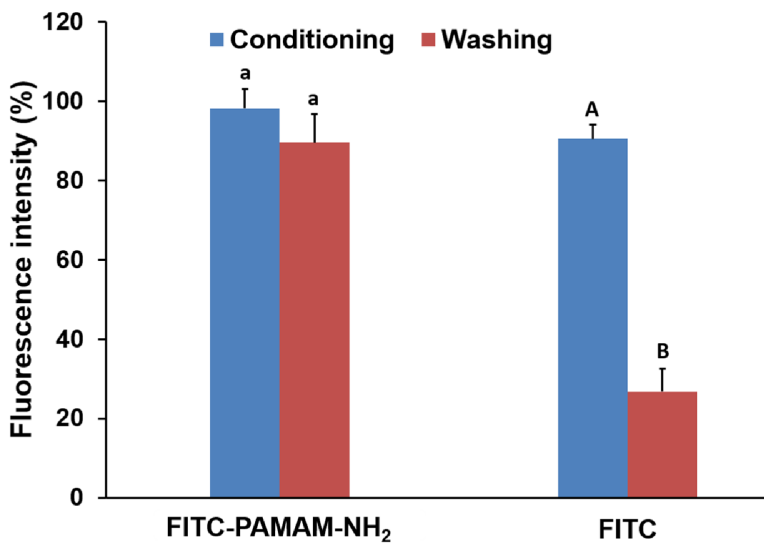

FIGURE 1 | The binding capacity of PAMAM-NH $\mathrm{H}_{2}$ to demineralized dentin. (A) The ATR-IR spectrum of the demineralized dentin, after conditioning with CHX or PAMAM-NH $\mathrm{H}_{2}$ and after washing with PBS. (B) The CLSM images of the demineralized dentin immobilized with FITC-labeled PAMAM-NH ${ }_{2}$ or free FITC, after washing

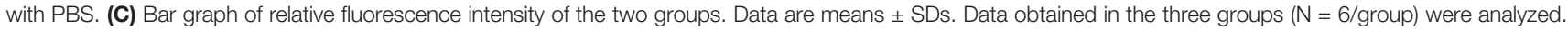
For FITC-PAMAM-NH $\mathrm{N}_{2}$, columns labeled with the same lowercase letters are not significantly different ( $\left.p>0.05\right)$. For FITC, columns labeled with different uppercase letters are significantly different $(p<0.05)$. ATR-IR, attenuated total reflectance-infrared; PBS, phosphate-buffered saline; CLSM, confocal laser scanning microscopy; FITC, fluorescein isothiocyanate.

PAMAM-NH $\mathrm{N}_{2}$ group before and after PBS washing ( $\left.\mathrm{p}>0.05\right)$. This result demonstrated that free FITC could not bind to the demineralized dentin surface and that PAMAM- $\mathrm{NH}_{2}$ had a good binding capacity to demineralize dentin.

\subsection{Antibacterial Activities}

A microdilution method was used to assess the antibacterial activity of PAMAM-NH 2 . MIC values of PAMAM- $\mathrm{NH}_{2}$ required to inhibit the visible growth of planktonic bacteria were 562.5 , 562.5 , and $750 \mu \mathrm{g} / \mathrm{ml}$ for $S$. mutans, A. naeslundii, and E. faecalis. MBEC values of PAMAM- $\mathrm{NH}_{2}$ on these three bacteria were 750 , 1,125 , and $3,500 \mu \mathrm{g} / \mathrm{ml}$ (Table 1). Figure 2 shows the CFU counts of $S$. mutans, A. naeslundii, and E. faecalis biofilms after treatment with deionized water, PAMAM- $\mathrm{NH}_{2}$, or $2 \% \mathrm{CHX}$. For these three bacteria, control dentin blocks (without cavity cleanser) all had the highest CFU. Dentin blocks treated with the PAMAM- $\mathrm{NH}_{2}$ and $2 \% \mathrm{CHX}$ significantly reduced viable bacteria in the biofilms, compared with dentin blocks without cavity cleanser $(\mathrm{p}<0.05)$. No significant difference was found between the PAMAM- $\mathrm{NH}_{2}$ and the $2 \% \mathrm{CHX}(\mathrm{p}>0.05)$. These results showed that PAMAM- $\mathrm{NH}_{2}$ cavity cleanser had inhibitory effects on bacteria grown on dentin blocks.

Figure 3A shows representative CLSM images of the distribution of $S$. mutans, A. naeslundii, and E. faecalis biofilms stained with live/dead stains. For all S. mutans, A. naeslundii, and E. faecalis, biofilms grown on control dentin blocks (without

TABLE 1 | MIC and MBEC values of PAMAM-NH $\mathrm{H}_{2}$ against Streptococcus mutans, Actinomyces naeslundii, and Enterococcus faecalis.

\begin{tabular}{lcc}
\hline Bacteria & MIC $(\boldsymbol{\mu} \mathbf{g} / \mathbf{m l})$ & MBEC $(\boldsymbol{\mu g} / \mathbf{m l})$ \\
\hline S. mutans & 562.5 & 750 \\
A. naeslundii & 562.5 & 1,125 \\
E. faecalis & 750 & 3,500 \\
\hline
\end{tabular}

MIC, minimum inhibitory concentration; MBEC, minimum biofilm eradication concentration. 


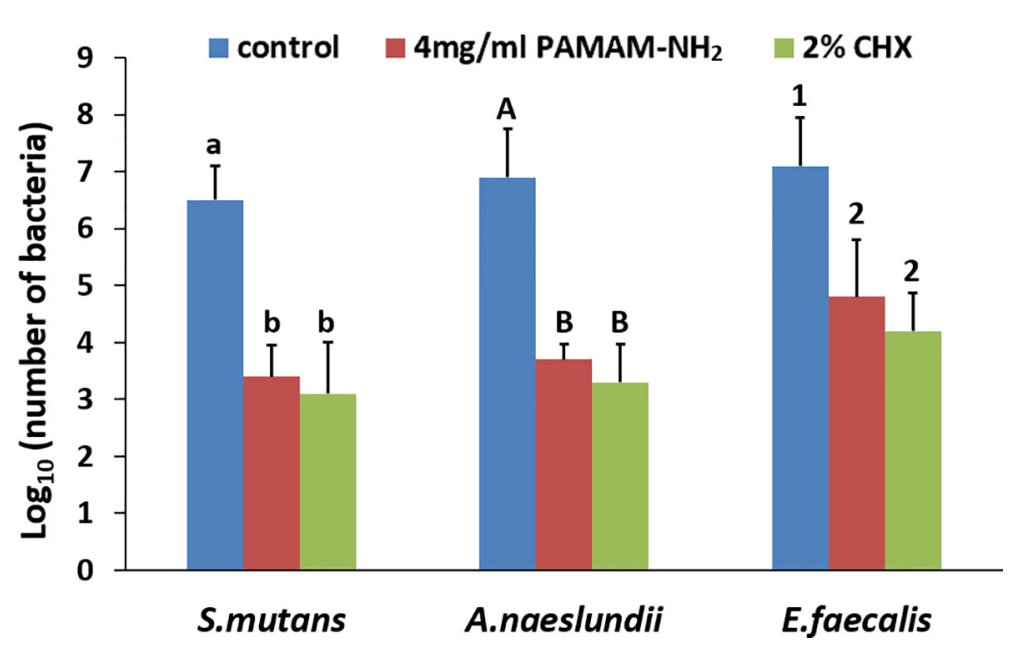

FIGURE 2 | CFU counts of Streptococcus mutans, Actinomyces naes/undii, or Enterococcus faecalis grown on dentin blocks for the deionized water control and the two cavity cleansers groups. Values are mean and SDs. Data obtained in the three groups ( $N=6 / g r o u p)$ were analyzed. For each bacterium strain, columns labeled with different letters or numbers are significantly different $(p<0.05)$. CFU, colony-forming unit.

cavity cleanser) consisted of primarily live bacteria, with small amounts of dead bacteria. In contrast, biofilms in the PAMAM$\mathrm{NH}_{2}$ and $2 \% \mathrm{CHX}$ dentin blocks showed primarily dead bacteria and a higher dead/live bacteria ratio as compared with the control group ( $\mathrm{p}<0.05$, Figure $3 \mathbf{B}$ ), which indicates that PAMAM- $\mathrm{NH}_{2-}$ and $2 \% \mathrm{CHX}$-pretreated dentin possessed antimicrobial activity. There was no significant difference in the antibacterial effect between the PAMAM- $\mathrm{NH}_{2}$ and $2 \%$ CHX groups ( $p>0.05$, Figure 3B).

\subsection{Inhibitory Effect of PAMAM- $\mathrm{NH}_{2}$ on Matrix Metalloproteinases}

The inhibitory effects of different concentrations of PAMAM$\mathrm{NH}_{2}$ on soluble MMPs are shown in Figure 4. The relative percentages of rhMMP-9 inhibitor by the GM6001 (kit inhibitor control) were $97.02 \% \pm 2.10 \%$. Inhibition of rhMMP-9 by PAMAM- $\mathrm{NH}_{2}$ at concentrations higher than $4 \mathrm{mg} / \mathrm{ml}$ (4 to 16 $\mathrm{mg} / \mathrm{ml}$ ) was comparable with that of the GM6001 group (inhibitor control) ( $\mathrm{p}>0.05$ ). The anti-MMP activities of PAMAM- $\mathrm{NH}_{2}$ at concentrations ranging from 0.5 to $2 \mathrm{mg} / \mathrm{ml}$ were significantly lower than those of the kit inhibitor control $(\mathrm{p}<0.05)$.

The in situ zymography technique enables screening of the relative proteolytic activities directly within dentin hybrid layers. Representative CLSM images of dentin pretreated with deionized water (control), PAMAM- $\mathrm{NH}_{2}$, and $2 \% \mathrm{CHX}$ are shown in Figure 5A. Figure 5B summarizes the relative percentage areas of hybrid layers in the three groups that showed green fluorescence after coming in contact with the highly quenched fluoresceinconjugated gelatin. For the control dentin slabs pretreated with deionized water, an intense green fluorescence was detected within the hybrid layers, reaching $88.3 \% \pm 5.2 \%$ fluorescence intensity. In contrast, the HLs in the experimental groups pretreated with 4 $\mathrm{mg} / \mathrm{ml}$ of PAMAM-NH $\mathrm{N}_{2}$ and $2 \% \mathrm{CHX}$ showed weak green fluorescence, with an intensity value of $22.6 \% \pm 4.1 \%$ and
$18.6 \% \pm 4.4 \%$, respectively. These fluorescence values were significantly lower than those of the control group $(\mathrm{p}<0.05)$. No significant difference was found between the PAMAM- $\mathrm{NH}_{2}$ group and the $2 \% \mathrm{CHX}$ group ( $\mathrm{p}>0.05$ ).

\subsection{Assessment of the Impact of PAMAM-NH ${ }_{2}$ on Resin-Dentin Bonding}

A double-fluorescence technique was employed to evaluate the permeability of the resin-dentin interface created by the etchand-rinse adhesive system under simulated pulpal pressure. The fluorescence representative images (separate channels; red for adhesive and green for water) of the permeability of adhesive are shown in Figure 6A. The adhesive infiltration data that are expressed as the relative percentage of red adhesive at the site of the dentinal tubules are presented in Figure 6B. In the control groups, the red adhesive sufficiently infiltrated into the dentinal tubules, as suggested by the presence of dense, branch-like resin tags at the resin-dentin interface. The relative percentages of the permeability were $91.2 \% \pm 4.9 \%$. At the bonded interface pretreated with PAMAM- $\mathrm{NH}_{2}$ or $2 \% \mathrm{CHX}$, the shape and depth of the resin tags were analogous to those groups in the control groups, reaching $88.5 \% \pm 7.1 \%$ and $93.7 \% \pm 5.8 \%$ permeability, respectively. There was no significant difference among these three groups in adhesive permeability values $(\mathrm{p}<0.05)$.

Tensile bond strength for each cavity cleanser group is shown in Figure 7. For both commercial adhesives PB and SBP, there was no significant difference among the control (without cavity cleanser), PAMAM- $\mathrm{NH}_{2}$, and $2 \% \mathrm{CHX}$ groups ( $\mathrm{p}>0.05$ ). Using PAMAM- $\mathrm{NH}_{2}$ cavity cleanser before adhesive application did not adversely affect the tensile bond strength of either adhesive. The two adhesive groups had similar failure mode distribution (Table 2). Low bond strength values tend to fail within the adhesive. Failure modes for all test beams exhibited obvious tendency of mixed failures, with a small distribution of cohesive failure in resin composite and cohesive failure in dentin. 
A

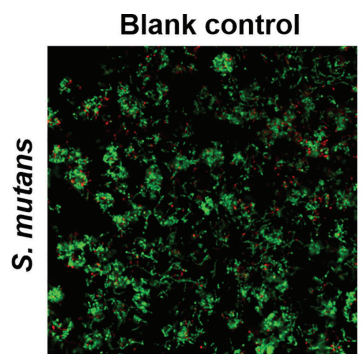

4mg/mI PAMAM-NH ${ }_{2}$
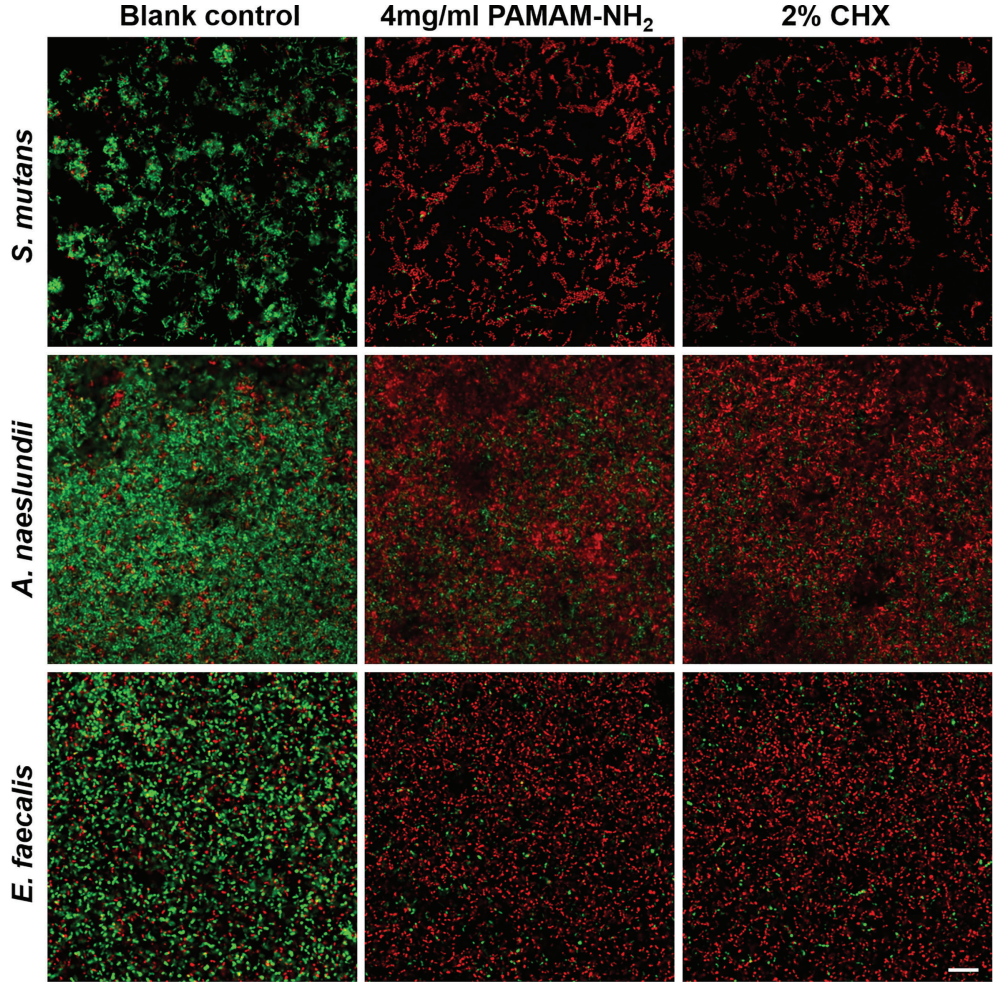

B

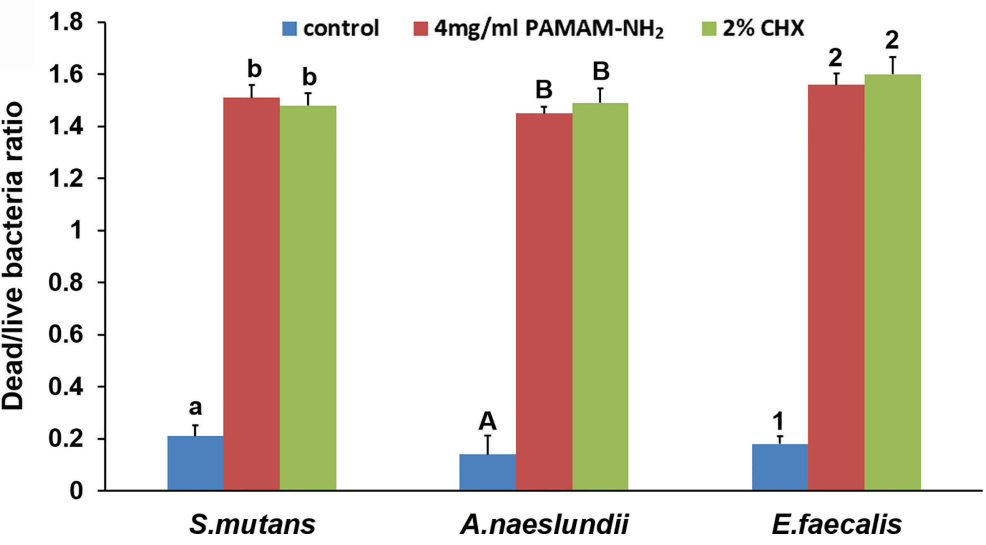

FIGURE 3 | (A) Representative CLSM images of Streptococcus mutans, Actinomyces naes/undii, or Enterococcus faecalis (live, green; dead, red) grown on dentin blocks after application of deionized water (control), and $4 \mathrm{mg} / \mathrm{ml}$ of PAMAM- $\mathrm{NH}_{2}$ or $2 \% \mathrm{CHX}$ as cavity cleansers. Bars $=20 \mu \mathrm{m}$. (B) Bar chart of the dead/live bacteria ratio of the three groups based on analysis of the live-dead staining profiles of the dentin blocks. Values are means and SDs. Data obtained in the three groups ( $N=6$ /group) were analyzed. For each bacterium strain, columns labeled with different letters or numbers are significantly different $(p<0.05)$. CLSM, confocal laser scanning microscopy

\subsection{Cytotoxicity Assay}

The cytotoxicity of PAMAM- $\mathrm{NH}_{2}$ on HDPCs and L929 at various concentrations from 0.5 to $8 \mathrm{mg} / \mathrm{ml}$ was evaluated using the CCK-8 assay (Figure 8). For both cells HDPCs and L929, there was no significant difference among the groups with PAMAM- $\mathrm{NH}_{2}$ at concentrations lower than $4 \mathrm{mg} / \mathrm{ml} \mathrm{(0.5} \mathrm{to} 4$ $\mathrm{mg} / \mathrm{ml})(\mathrm{p}>0.05)$. Good cell viability in the range of $80 \%-110 \%$ was observed with PAMAM- $\mathrm{NH}_{2}$ at concentrations lower than
$4 \mathrm{mg} / \mathrm{ml}(0.5$ to $4 \mathrm{mg} / \mathrm{ml})$, which demonstrates that PAMAM$\mathrm{NH}_{2}$ has low cytotoxicity at working concentrations.

\section{DISCUSSION}

CHX is commonly recommended to be used as cavity cleanser in the clinic. Nevertheless, weak binding affinity for collagen and 


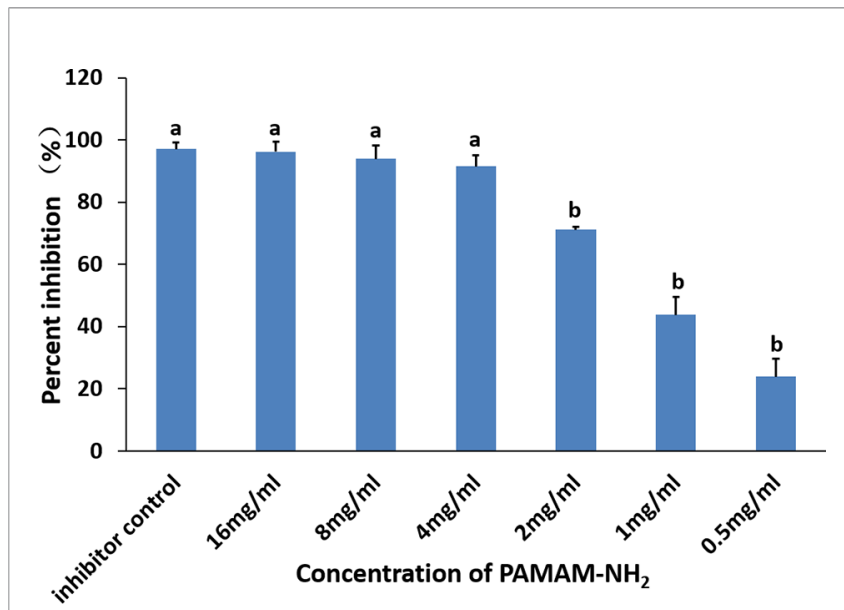

FIGURE 4 | Inhibitory effect of PAMAM- $\mathrm{NH}_{2}$ concentration on soluble rhMMP-9. Data are means \pm SDs. Data obtained in the three groups $(N=6$ / group) were analyzed. Columns identified with the different lowercase letters are significantly different $(p<0.05)$.

the leaching-out property make CHX short-lived, thus limiting its potential clinical applications. Therefore, it is in demand to develop a new cavity cleanser with long-term antimicrobial and anti-proteolytic activities.

PAMAM- $\mathrm{NH}_{2}$ dendrimer is categorized as one type of hyperbranched polymeric macromolecules and has been extensively investigated as a promising antibacterial agent (Castonguay et al., 2012; Mintzer et al., 2012). However, the dentinal tubules are filled with fluid. Intrapulpal pressure enables constant replenishment of intrinsic water from the pulp chamber to the dentin surface. Therefore, the binding capacity of PAMAM-NH $\mathrm{H}_{2}$ to demineralized dentin is important to fulfill its long-term antimicrobial and anti-proteolytic effects. In this study, ATR-FTIR spectroscopy and CLSM of the demineralized dentin, after being conditioned with $4 \mathrm{mg} / \mathrm{ml}$ of PAMAM- $\mathrm{NH}_{2}$ or $2 \% \mathrm{CHX}$ and after being washed with PBS, respectively, were first performed. From the present results, characteristic peaks of $\mathrm{CHX}$ or PAMAM-NH $\mathrm{H}_{2}$ were clearly observed in ATR-FTIR spectra after dentin discs were conditioned with 2\% $\mathrm{CHX}$ or PAMAM-NH${ }_{2}$ (Figure 1A), indicating that both $\mathrm{CHX}$ and PAMAM-NH $\mathrm{H}_{2}$ could bind to the demineralized dentin surface. However, the characteristic peaks of $\mathrm{CHX}$ disappeared in $2 \% \mathrm{CHX}$ conditioning dentin surface, after being washed with PBS, demonstrating that $2 \% \mathrm{CHX}$ had a weak binding capacity to demineralized dentin surface. In contrast, PAMAM- $\mathrm{NH}_{2}$-conditioned dentin surface retained large amounts of PAMAM- $\mathrm{NH}_{2}$ following washing, as suggested by the presence of the characteristic amide peaks. The results demonstrated that the binding capacity of PAMAM- $\mathrm{NH}_{2}$ on demineralized dentin surface was much stronger than that of $2 \% \mathrm{CHX}$, and the binding was strong enough to resist PBS washing. These results were also confirmed by CLSM. CLSM images (Figure 1B) showed that the yellow-green fluorescence was visible all over the surface of the FITC-labeled PAMAM-NH $\mathrm{N}_{2}$ sample with an intensity value of $89.6 \% \pm 3.5 \%$ (Figure 1C), while little fluorescence observed on the free FITC sample reaching $26.8 \% \pm 5.7 \%$ fluorescence intensity after PBS washing. Thus, PAMAM- $\mathrm{NH}_{2}$ is considered to have a better binding capacity to demineralized dentin, as it can resist PBS washing. The results
A
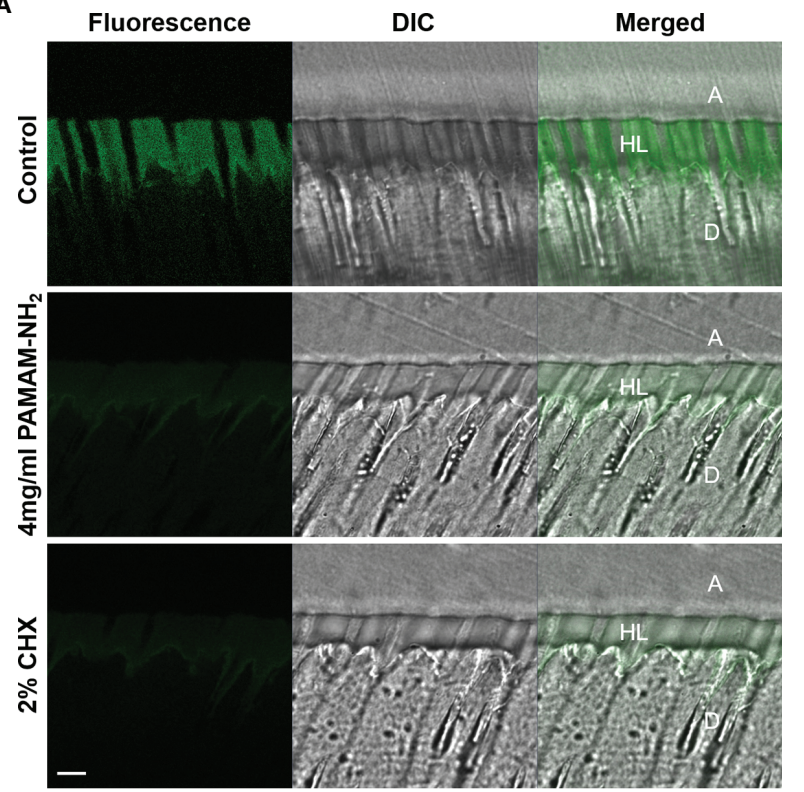

B

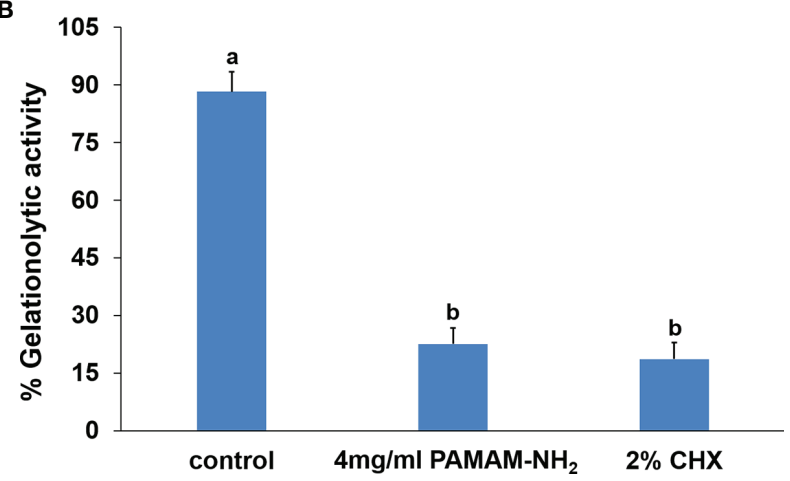

FIGURE 5 | (A) Representative CLSM images of in situ zymography performed in resin-dentin interfaces pretreated with the deionized water control, $4 \mathrm{mg} / \mathrm{ml}$ PAMAM- $\mathrm{NH}_{2}$ cavity cleanser, or the $2 \% \mathrm{CHX}$ cavity cleanser prior to adhesive application. Bars $=5 \mu \mathrm{m}$. A, adhesive layer; HL, hybrid layer; D, dentin. Green channel: fluorescence derived from dequenched fluorescein released after breaking down of the highly quenched fluorescein-conjugated extrinsic gelatin source into smaller peptides. DIC, differential interference contrast image of the resin-dentin interface. (B) Quantified in situ zymography data depicting the percentage of hybrid layers that exhibit activity against extrinsic fluorescein-conjugated gelatin in the deionized water control, $4 \mathrm{mg} / \mathrm{ml}$ of PAMAM- $\mathrm{NH}_{2}$ cavity cleanser, or the $2 \% \mathrm{CHX}$ cavity cleanser. Data are means \pm SDs. Data obtained in the three groups ( $N=6 / g r o u p)$ were analyzed. Columns labeled with different lowercase letters are significantly different $(p<0.05)$. CLSM, confocal laser scanning microscopy.

were consistent with a previous study, which also showed that PAMAM$\mathrm{NH}_{2}$ had a good binding capacity to the demineralized dentin (Liang et al., 2015). The stronger binding capacity of PAMAM- $\mathrm{NH}_{2}$ over $2 \%$ $\mathrm{CHX}$ is likely attributed to its great number of functional groups. The external amine groups are positively charged groups, and the internal amide groups are negatively charged groups. These charged groups may help the molecule to bind to the collagen fibrils via electrostatic interactions (Liang et al., 2015). Thus, the first and third hypotheses 


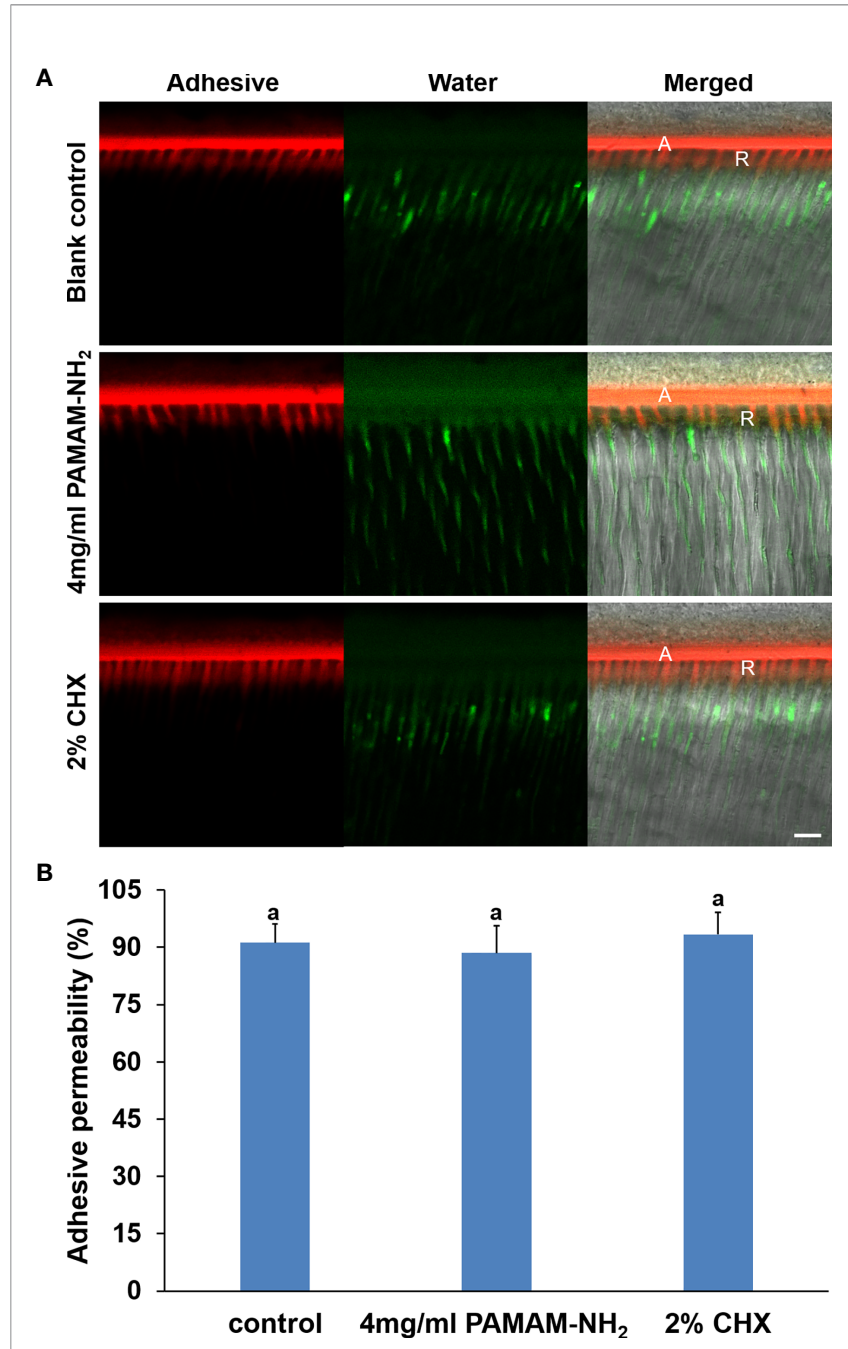

FIGURE 6 | (A) Representative CLSM images illustrating adhesive permeability of resin-dentin interfaces with simulated pulpal pressure $(20 \mathrm{~cm}$ water pressure) in the control, $4 \mathrm{mg} / \mathrm{ml}$ of PAMAM- $\mathrm{NH}_{2}$, and $2 \% \mathrm{CHX}$ groups. Bars $=10 \mu \mathrm{m}$. A, adhesive layer; $\mathrm{R}$, resin tag. Red channel, adhesive fluorescence; green channel, water containing fluorescent dye. (B) Bar chart comparing the relative adhesive permeability of the resin-dentin interfaces in the control, $4 \mathrm{mg} / \mathrm{ml}$ of PAMAM- $\mathrm{NH}_{2}$, and $2 \% \mathrm{CHX}$ groups. Data are means \pm SDs. Data obtained in the three groups ( $N=6 /$ group) were analyzed. Columns labeled with letters of the same case are not significantly different ( $p$ > 0.05). CLSM, confocal laser scanning microscopy.

that "the PAMAM- $\mathrm{NH}_{2}$ cavity cleanser has long-term inhibitory effects on bacteria and endogenous dentin proteases" are partially validated by the binding experiments.

Although PAMAM- $\mathrm{NH}_{2}$ has been extensively investigated as a promising antibacterial agent (Castonguay et al., 2012; Mintzer et al., 2012), there are just few reports whether PAMAM- $\mathrm{NH}_{2}$ has inhibitory effects on oral pathogens. S. mutans and $A$. naeslundii are cariogenic oral pathogens associated with secondary caries (Mo et al., 2010), which is described as a multifactorial infectious disease that is characterized by oral microbiome dysbiosis with the elevation of cariogenic bacteria (Tanner et al., 2016). E. faecalis is a common bacterium in filled

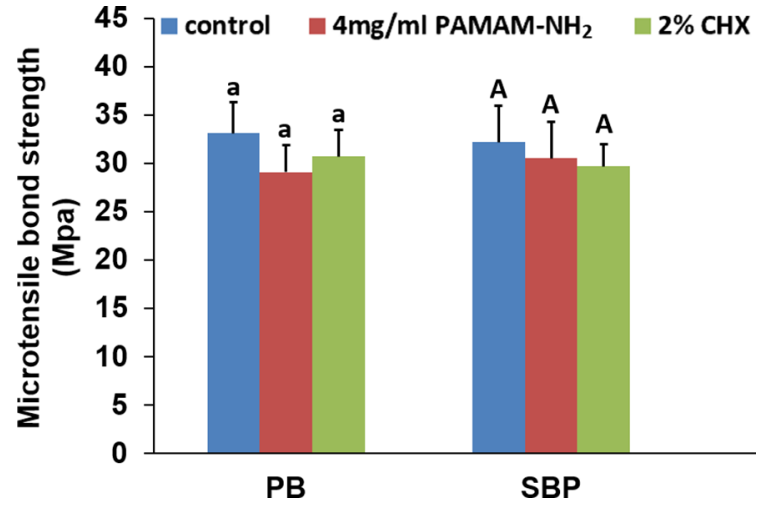

FIGURE 7 | The microtensile bond strength of dentin created with the two different adhesives pretreated with different cavity cleansers. Data are means \pm SDs. Data obtained in the three groups ( $N=6 /$ group) were analyzed. For $\mathrm{PB}$, columns labeled with same lowercase letters are not significantly different ( $p>0.05)$. For SBP, columns labeled with same uppercase letters are not significantly different $(p>0.05)$.

root canals with persistent apical periodontitis (Wang et al., 2012). Because establishment of coronal seal with composite resin is frequently performed after placement of root fillings to prevent reinfection of the obturated canal space, the antibacterial activity of PAMAM- $\mathrm{NH}_{2}$ on E. faecalis was also evaluated (Guo et al., 2019). Therefore, these three microbes were chosen to evaluate the antibacterial properties of PAMAM-NH $\mathrm{H}_{2}$ cavity cleanser. From the results of antibacterial activities, the antibacterial effect of PAMAM- $\mathrm{NH}_{2}$ was comparable with that of $2 \% \mathrm{CHX}$. Thus, the first hypothesis that "the PAMAM-NH cavity cleanser has long-term inhibitory effects on bacteria grown on dentin blocks" is totally validated. PAMAM- $\mathrm{NH}_{2}$ has a great number of positive charges on the protonated amino terminal groups on its exterior, which confers a strong affinity for bacterial surface with negative charges by electrostatic interactions. Such initial electrostatic interactions subsequently promote the disruption of anionic bacterial cell membranes and peptidoglycan, leading to leakage of cytoplasmic components and bacteria death (Castonguay et al., 2012; Mintzer et al., 2012; Gou et al., 2017). Due to its ability to damage bacteria through non-specific physical mechanisms rather than by targeting specific molecules (Wang et al., 2010), cationic PAMAM- $\mathrm{NH}_{2}$ dendrimer works against not only non-resistant bacteria but also currently antibiotic-resistant strains and is less likely to contribute to the development of bacteria resistance (Xue et al., 2013).

Dental plaque is a dynamic and complex ecosystem consisting of multispecies microbial communities. The development of dental caries is closely associated with imbalance in microbial equilibrium rather than a single pathogenic species (Filoche et al., 2010). Changes in the oral environment, such as food intake or saliva flow, may trigger a shift in dental plaque, in which acidogenic/aciduric species are selectively enriched at the expense of those less aciduric commensal residents (Filoche et al., 2010; Zheng et al., 2015). These changes lead to acid accumulation 
TABLE 2 | Percentage distribution of failure modes (A: adhesive failure; M: mixed failure; CC: cohesive failure in resin composite; CD: cohesive failure in dentin).

\begin{tabular}{|c|c|c|c|c|c|c|}
\hline \multirow[t]{2}{*}{ Failure mode } & \multicolumn{3}{|c|}{ Prime \& Bond $\mathrm{NT}^{\mathrm{TM}}$} & \multicolumn{3}{|c|}{ Adper $^{\mathrm{TM}}$ Single Bond Plus } \\
\hline & Control & PAMAM-NH & $\mathrm{CHX}$ & Control & PAMAM-NH ${ }_{2}$ & $\mathrm{CHX}$ \\
\hline$A$ & 10 & 11 & 8 & 11 & 14 & 7 \\
\hline $\mathrm{M}$ & 42 & 39 & 40 & 41 & 39 & 45 \\
\hline$C D$ & 3 & 5 & 8 & 1 & 1 & 3 \\
\hline $\mathrm{CC}$ & 5 & 5 & 4 & 7 & 6 & 5 \\
\hline Total & 60 & 60 & 60 & 60 & 60 & 60 \\
\hline
\end{tabular}

and subsequent $\mathrm{pH}$ declination, thus producing dental plaque with a more cariogenic composition. Several clinical studies confirmed that the diversity of the microbiota in carious lesions could be decreased by the establishment and dominance of acidogenic/ aciduric species (Costalonga and Herzberg, 2014; Kianoush et al., 2014), and a higher proportion of $S$. mutans has been observed in lesion spots (Ge et al., 2008). In our study, with the stress from the PAMAM- $-\mathrm{NH}_{2}$ cavity cleanser, the enriched acidogenic/aciduric species (e.g., S. mutans and A. naeslundii) were obviously inhibited and appeared to lose their dominant position, which has a potential effect in maintaining a healthy oral microbial equilibrium. Further biofilm composition studies and possible mechanism studies are required to support the potential biofilm species modulation of the presently developed bioactive PAMAM- $\mathrm{NH}_{2}$ cavity cleaner.

The hybrid layer remains the weakest link within the bonded interface due to its degradation via endogenous dentin proteases. They become exposed and activated during the acid-etching and adhesive placement steps of contemporary bonding procedures, which contributes to the degradation of exposed collagen fibrils within the hybrid layers. Therefore, our present study also aimed to explore whether PAMAM- $\mathrm{NH}_{2}$ can inhibit endogenous MMP in the dentin matrix. Soluble rhMMP-9 was employed for examining the potential inhibitory effect of PAMAM- $\mathrm{NH}_{2}$ by Sensolyte assay kits. The results of the quantitative assay

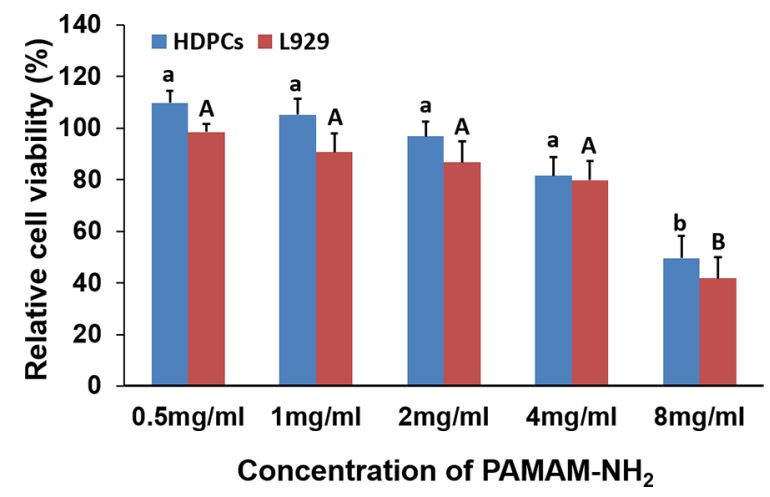

FIGURE 8 | Cytotoxicity assay of PAMAM-NH $\mathrm{H}_{2}$ to HDPCs and L929 at different concentrations by CCK-8 assay. Data are means \pm SDs. Data obtained in the three groups ( $N=6 /$ group) were analyzed. For HDPCs, columns labeled with same lowercase letters are not significantly different $(p>$ 0.05). For L929, columns labeled with same uppercase letters are not significantly different $(p>0.05)$. HDPCs, human dental pulp cells. demonstrated that the extent of rhMMP-9 inhibition was proportional to PAMAM- $\mathrm{NH}_{2}$ concentrations. The anti-MMP9 activities of PAMAM- $\mathrm{NH}_{2}$ at concentrations higher than $4 \mathrm{mg} /$ $\mathrm{ml}$ (4 to $16 \mathrm{mg} / \mathrm{ml}$ ) were comparable with those of the GM6001 control group $(p>0.05)$. Hence, the second hypothesis that "the PAMAM- $\mathrm{NH}_{2}$ cavity cleanser has inhibitory effects on soluble MMP-9 activities" is validated. However, this experiment confirmed that PAMAM- $\mathrm{NH}_{2}$ has inhibitory effects on exogenous rhMMP-9. Its effect on endogenous MMP-9 embedded within collagen matrix should also be investigated. In the present study, in situ zymography was employed to detect the proteolytic activity of the endogenous MMP-9 directly within dentin hybrid layers (Frederiks and Mook, 2004; Gou et al., $2018 b$ ). According to the concentrations of PAMAM-NH $\mathrm{NH}_{2}$ tested from antibacterial activities and inhibitory effects on exogenous rhMMP-9, the concentration of $4 \mathrm{mg} / \mathrm{ml}$ of PAMAM- $\mathrm{NH}_{2}$ was used for the following experiments. For the control groups, extensive green fluorescence was detected within the hybrid layers, indicating strong gelatinolytic activity. In contrast, dentin slabs pretreated with $4 \mathrm{mg} / \mathrm{ml}$ of PAMAM- $\mathrm{NH}_{2}$ exhibited weak gelatinolytic activity within the hybrid layers after incubation for $48 \mathrm{~h}$, which is significantly lower than that of the control group. Thus, the third hypothesis that "the PAMAM$\mathrm{NH}_{2}$ cavity cleanser has long-term inhibitory effects on endogenous dentin proteases" is totally validated.

Although the functional mechanism of inhibitory effects of PAMAM- $\mathrm{NH}_{2}$ on dentin proteases is still not clear, several factors may have contributed to the inhibitory effect. The catalytic domains of MMPs contain cysteine-rich sites, including negatively charged glutamic acid residues (Tezvergil-Mutluay et al., 2011). PAMAM- $\mathrm{NH}_{2}$ may bind electrostatically to the negatively charged glutamic acid residues with a great number of positive charges on the protonated amino groups on its exterior. This non-specific binding can change the configuration of the catalytic site of the MMPs by electrostatic interaction with the negatively charged glutamic acid residues, sterically blocking the active site and inhibiting the activation of MMPs. Additionally, amineterminated dendritic polymers were reported as a multifunctional chelating agent for heavy metal ion removals (Mohseni et al., 2019). Accordingly, we surmise that the inhibitory effect of PAMAM- $\mathrm{NH}_{2}$ on MMPs is potentially related to its potency of chelation on $\mathrm{Zn}^{2+}$ and $\mathrm{Ca}^{2+}$. MMPs are a family of $\mathrm{Zn}$ - and $\mathrm{Ca}$-dependent enzymes (Zitka et al., 2010). PAMAM-NH 2 may chelate $\mathrm{Zn}^{2+}$ or $\mathrm{Ca}^{2+}$ that can be bound to the $\mathrm{Zn}^{2+}$ - and $\mathrm{Ca}^{2+}$-active sites of the catalytic domain of MMPs (Wu et al., 2019), which is also conductive to inhibiting MMP activities. 
Adhesive infiltration into the dentinal tubules is paramount for preserving the integrity of resin-dentin bonding. To evaluate the effect of PAMAM- $\mathrm{NH}_{2}$ on the adhesive permeation and morphology of the resin-dentin interface, the bonded dentin interface was observed by a double-fluorescence CLSM technique. From the present results, the resin tag shared a morphological similarity in both experimental and control groups. The quantitative analysis of permeability also demonstrated that PAMAM- $\mathrm{NH}_{2}$ as a cavity cleanser did not decrease the infiltration of adhesive monomers.

The dentin tensile bond strengths were also performed to evaluate whether the application of PAMAM- $\mathrm{NH}_{2}$ adversely affects the tensile bond strength of commercial adhesive. The results showed that pretreatment of dentin surface with PAMAM- $\mathrm{NH}_{2}$ or $2 \% \mathrm{CHX}$ had no adverse effect on the dentin bond strength. Thus, the fourth hypothesis that "treatment of dentin surface with PAMAM- $\mathrm{NH}_{2}$ cavity cleanser does not adversely affect dentin bond strength" is validated.

In our study, the relative cell viability in the range of $80 \%-$ $110 \%$ was observed with PAMAM- $\mathrm{NH}_{2}$ at concentrations equal to or lower than $4 \mathrm{mg} / \mathrm{ml}(0.5$ to $4 \mathrm{mg} / \mathrm{ml})$, which is considered non-cytotoxic (Zou et al., 2011; International Organization for Standardization, 2009) and has potential clinical application at working concentration.

\section{CONCLUSION}

Within the limitations of the present study, it may be concluded that PAMAM- $\mathrm{NH}_{2}$ cavity cleanser developed in this study could provide simultaneous long-term antimicrobial and antiproteolytic activities for eliminating secondary caries that results from a dysbiosis in the oral microbiome and preventing hybrid layers from degradation due to its good binding capacity to dentin collagen matrix, which are crucial for the maintenance of resindentin bond durability. Although the price of the commercially available cavity cleaner-2\% CHX may be slightly lower than that of PAMAM- $\mathrm{NH}_{2}$, long-term antibacterial and anti-proteolytic activities may give PAMAM- $\mathrm{NH}_{2}$ an advantage over $\mathrm{CHX}$.

\section{REFERENCES}

Blackburn, R. S., Harvey, A., Kettle, L. L., Manian, A. P., Payne, J. D., and Russell, S. J. (2007). Sorption of Chlorhexidine on Cellulose: Mechanism of Binding and Molecular Recognition. J. Phys. Chem. B. 111, 8775-8784. doi: 10.1021/ jp070856r

Breschi, L., Mazzoni, A., Ruggeri, A., Cadenaro, M., Di Lenarda, R., and De Stefano Dorigo, E. (2008). Dental Adhesion Review: Aging and Stability of the Bonded Interface. Dent. Mater. 24, 90-101. doi: 10.1016/j.dental.2007.02.009

Castonguay, A., Ladd, E., van de Ven, T. G. M., and Kakkar, A. (2012). Dendrimers as Bactericides. N. J. Chem. 36, 199-204. doi: 10.1039/C1NJ20481E

Costalonga, M., and Herzberg, M. C. (2014). The Oral Microbiome and the Immunobiology of Periodontal Disease and Caries. Immunol. Lett. 162, 22-38. doi: 10.1016/j.imlet.2014.08.017

Ersin, N. K., Aykut, A., Candan, U., Onçă̆, O., Eronat, C., and Kose, T. (2008). The Effect of a Chlorhexidine Containing Cavity Disinfectant on the Clinical Performance of High-Viscosity Glass-Ionomer Cement Following ART: 24Month Results. Am. J. Dent. 21, 39-43. doi: 10.1016/j.tripleo.2007.09.017

\section{DATA AVAILABILITY STATEMENT}

The original contributions presented in the study are included in the article/supplementary material. Further inquiries can be directed to the corresponding authors.

\section{ETHICS STATEMENT}

The studies involving human participants were reviewed and approved by Clinical Scientific Research Ethics Committee of Hospital of Stomatology, Lanzhou University. The patients/ participants provided their written informed consent to participate in this study.

\section{AUTHOR CONTRIBUTIONS}

YG contributed to the conception, design, data acquisition, analysis, and interpretation and drafted and revised the manuscript. WJ contributed to the data acquisition and interpretation and drafted the manuscript. YaH contributed to the data acquisition and analysis and drafted the manuscript. YL, $\mathrm{RS}, \mathrm{YuH}, \mathrm{ZW}$, and JL contributed to the design, data analysis, and interpretation and drafted the manuscript. BL contributed to the data analysis and interpretation and critically revised the manuscript. All authors contributed to the article and approved the submitted version.

\section{FUNDING}

This work was supported by the National Natural Science Foundation of China grant 82001034, Natural Science Foundation in Gansu Province of China grant 20JR10RA595, Fundamental Research Funds for the Central Universities of Lanzhou University grant lzujbky-2020-53, and School/Hospital of Stomatology, Lanzhou University grant lzukqky-2019y15 (YG).

Filoche, S., Wong, L., and Sissons, C. H. (2010). Oral Biofilms: Emerging Concepts in Microbial Ecology. J. Dent. Res. 89, 8-18. doi: 10.1177/0022034509351812

Frassetto, A., Breschi, L., Turco, G., Marchesi, G., Di Lenarda, R., Tay, F. R., et al. (2016). Mechanisms of Degradation of the Hybrid Layer in Adhesive Dentistry and Therapeutic Agents to Improve Bond Durability-A Literature Review. Dent. Mater. 32, e41-e53. doi: 10.1016/j.dental.2015.11.007

Frederiks, W. M., and Mook, O. R. (2004). Metabolic Mapping of Proteinase Activity With Emphasis on in Situ Zymography of Gelatinases: Review and Protocols. J. Histochem. Cytochem. 52, 711-722. doi: 10.1369/jhc.4R6251.2004

Ge, Y., Caufield, P. W., Fisch, G. S., and Li, Y. (2008). Streptococcus Mutans and Streptococcus Sanguinis Colonization Correlated With Caries Experience in Children. Caries Res. 42, 444-448. doi: 10.1159/000159608

Gou, Y. P., Li, J. Y., Meghil, M. M., Cutler, C. W., Xu, H. H. K., Tay, F. R., et al. (2018a). Quaternary Ammonium Silane-Based Antibacterial and AntiProteolytic Cavity Cleanser. Dent. Mater. 34, 1814-1827. doi: 10.1016/ j.dental.2018.10.001

Gou, Y. P., Meghil, M. M., Pucci, C. R., Breschi, L., Pashley, D. H., Cutler, C. W., et al. (2018b). Optimizing Resin-Dentin Bond Stability Using a Bioactive 
Adhesive With Concomitant Antibacterial Properties and Anti-Proteolytic Activities. Acta Biomater. 75, 171-182. doi: 10.1016/j.actbio.2018.06.008

Gou, Y. P., Yang, X., He, L. B., Xu, X. Y., Liu, Y. P., Liu, Y. B., et al. (2017). BioInspired Peptide Decorated Dendrimers for a Robust Antibacterial Coating on Hydroxyapatite. Polym. Chem. 8, 4264-4279. doi: 10.1039/C7PY00811B

Guo, J. M., Makvandi, P., Wei, C. C., Chen, J. H., Xu, H. K., Breschi, L., et al. (2019). Polymer Conjugation Optimizes EDTA as a Calcium-Chelating Agent That Exclusively Removes Extrafibrillar Minerals From Mineralized Collagen. Acta Biomater. 90, 424-440. doi: 10.1016/j.actbio.2019.04.011

International Organization for Standardization. (2009). ISO 10993-5: 2009 (E). Available at: https://www.iso.org/obp/ui/\#iso.

Kianoush, N., Adler, C. J., Nguyen, K. A., Browne, G. V., Simonian, M., and Hunter, N. (2014). Bacterial Profile of Dentine Caries and the Impact of $\mathrm{pH}$ on Bacterial Population Diversity. PloS One 9, e92940. doi: 10.1371/journal.pone.0092940

Liang, K., Yuan, H., Li, J., Yang, J., Zhou, X., He, L., et al. (2015). Remineralization of Demineralized Dentin Induced by Amine-Terminated PAMAM Dendrimer. Macromol. Mater. Eng. 300, 107-117. doi: 10.1002/mame.201400207

Mazzoni, A., Tjäderhane, L., Checchi, V., Di Lenarda, R., Salo, T., Tay, F. R., et al. (2015). Role of Dentin MMPs in Caries Progression and Bond Stability. J. Dent. Res. 94, 241-251. doi: 10.1177/0022034514562833

Mintzer, M. A., Dane, E. L., O’Toole, G. A., and Grinstaff, M. W. (2012). Exploiting Dendrimer Multivalency To Combat Emerging and ReEmerging Infectious Diseases. Mol. Pharmaceut. 9, 342-354. doi: 10.1021/ mp2005033

Mo, S. S., Bao, W., Lai, G. Y., Wang, J., and Li, M. Y. (2010). The Microfloral Analysis of Secondary Caries Biofilm Around Class I and Class II Composite and Amalgam Fillings. BMC. Infect. Dis. 10:241. doi: 10.1186/1471-2334-10-241

Mohseni, M., Akbari, S., Pajootan, E., and Mazaheri, F. (2019). Amine-Terminated Dendritic Polymers as a Multifunctional Chelating Agent for Heavy Metal Ion Removals. Environ. Sci. Pollut. Res. Int. 26, 12689-12697. doi: 10.1007/s11356019-04765-3

Nyvad, B., and Kilian, M. (1987). Microbiology of the Early Colonization of Human Enamel and Root Surfaces In Vivo. Scand. J. Dent. Res. 95, 369-380. doi: 10.1111/j.1600-0722.1987.tb01627.x

Osorio, R., Yamauti, M., Osorio, E., Ruiz-Requena, M. E., Pashley, D., Tay, F., et al. (2011). Effect of Dentin Etching and Chlorhexidine Application on Metalloproteinase-Mediated Collagen Degradation. Eur. J. Oral. Sci. 119, 7985. doi: 10.1111/j.1600-0722.2010.00789.x

Scaffa, P. M., Vidal, C. M., Barros, N., Gesteira, T. F., Carmona, A. K., Breschi, L., et al. (2012). Chlorhexidine Inhibits the Activity of Dental Cysteine Cathepsins. J. Dent. Res. 91, 420-425. doi: 10.1177/0022034511435329

Slee, A. M., and Tanzer, J. M. (1979). Studies on the Relative Binding Affinities of Chlorhexidine Analogs to Cation Exchange Surfaces. J. Periodontal. Res. 14, 213-219. doi: 10.1111/j.1600-0765.1979.tb00225.x

Tanner, A. C., Kressirer, C. A., and Faller, L. L. (2016). Understanding Caries From the Oral Microbiome Perspective. J. Calif. Dent. Assoc. 44, 437-446.

Tay, F. R., Pashley, D. H., Loushine, R. J., Weller, R. N., Monticelli, F., and Osorio, R. (2006). Self-Etching Adhesives Increase Collagenolytic Activity in Radicular Dentin. J. Endod. 32, 862-868. doi: 10.1016/j.joen.2006.04.005

Tezvergil-Mutluay, A., Agee, K. A., Uchiyama, T., Imazato, S., Mutluay, M. M., Cadenaro, M., et al. (2011). The Inhibitory Effects of Quaternary Ammonium Methacrylates on Soluble and Matrix-Bound MMPs. J. Dent. Res. 90, 535-540. doi: $10.1177 / 0022034510389472$

Thompson, V., Craig, R. G., Curro, F. A., Green, W. S., and Ship, J. A. (2008). Treatment of Deep Carious Lesions by Complete Excavation or Partial
Removal: A Critical Review. J. Am. Dent. Assoc. 139, 705-712. doi: 10.14219/ jada.archive.2008.0252

Tjäderhane, L., Nascimento, F. D., Breschi, L., Mazzoni, A., Tersariol, I. L., Geraldeli, S., et al. (2013). Strategies to Prevent Hydrolytic Degradation of the Hybrid Layer-A Review. Dent. Mater. 29, 999-1011. doi: 10.1016/ j.dental.2013.07.016

Türkün, M., Türkün, L. S., Ergücü, Z., and Ateş, M. (2006). Is an Antibacterial Adhesive System More Effective Than Cavity Disinfectants? Am. J. Dent. 19, 166-170. doi: 10.1080/00016350600573191

Twetman, S. (2004). Antimicrobials in Future Caries Control? A Review With Special Reference to Chlorhexidine Treatment. Caries Res. 38, 223-229. doi: $10.1159 / 000077758$

Walsh, L. J., and Brostek, A. M. (2013). Minimum Intervention Dentistry Principles and Objectives. Aust. Dent. J. 58 Suppl. 1, 3-16. doi: 10.1111/adj.12045

Wang, B., Navath, R. S., Menjoge, A. R., Balakrishnan, B., Bellair, R., Dai, H., et al. (2010). Inhibition of Bacterial Growth and Intramniotic Infection in a Guinea Pig Model of Chorioamnionitis Using PAMAM Dendrimers. Int. J. Pharm. 395, 298-308. doi: 10.1016/j.ijpharm.2010.05.030

Wang, Q. Q., Zhang, C. F., Chu, C. H., and Zhu, X. F. (2012). Prevalence of Enterococcus Faecalis in Saliva and Filled Root Canals of Teeth Associated With Apical Periodontitis. Int. J. Oral. Sci. 4, 19-23. doi: 10.1038/ijos.2012.17

Wu, Q. A., Shan, T., Zhao, M., Mai, S., and Gu, L. (2019). The Inhibitory Effect of Carboxyl-Terminated Polyamidoamine Dendrimers on Dentine Host-Derived Matrix Metalloproteinases In Vitro in an Etch-and-Rinse Adhesive System. $R$. Soc Open Sci. 6, 182104. doi: 10.1098/rsos.182104

Xue, X., Chen, X., Mao, X., Hou, Z., Zhou, Y., Bai, H., et al. (2013). AminoTerminated Generation 2 Poly(Amidoamine) Dendrimer as a Potential BroadSpectrum, Nonresistance-Inducing Antibacterial Agent. AAPS. J. 15, 132-142. doi: 10.1208/s12248-012-9416-8

Zheng, X., Cheng, X., Wang, L., Qiu, W., Wang, S., Zhou, Y., et al. (2015). Combinatorial Effects of Arginine and Fluoride on Oral Bacteria. J. Dent. Res. 94, 344-353. doi: 10.1177/0022034514561259

Zitka, O., Kukacka, J., Krizkova, S., Huska, D., Adam, V., Masarik, M., et al. (2010). Matrix Metalloproteinases. Curr. Med. Chem. 17, 3751-3768. doi: 10.2174/ 092986710793213724

Zou, Y., Wang, W. M., Zhu, Y. N., and Yang, W. D. (2011). In Vitro Evaluation the Cytotoxicity of Dental Bonding Agents Through CCK-8 Assay. J. Oral. Sci. R. 27 (8), 673-675. doi: 10.13701/j.cnki.kqyxyj.2011.08.014

Conflict of Interest: The authors declare that the research was conducted in the absence of any commercial or financial relationships that could be construed as a potential conflict of interest.

Publisher's Note: All claims expressed in this article are solely those of the authors and do not necessarily represent those of their affiliated organizations, or those of the publisher, the editors and the reviewers. Any product that may be evaluated in this article, or claim that may be made by its manufacturer, is not guaranteed or endorsed by the publisher.

Copyright $\odot 2021$ Gou, Jin, He, Luo, Si, He, Wang, Li and Liu. This is an open-access article distributed under the terms of the Creative Commons Attribution License (CC BY). The use, distribution or reproduction in other forums is permitted, provided the original author(s) and the copyright owner(s) are credited and that the original publication in this journal is cited, in accordance with accepted academic practice. No use, distribution or reproduction is permitted which does not comply with these terms. 